\title{
O PÍFANO NORDESTINO COMO INSTRUMENTO DE MUSICALIZAÇÃO NO ENSINO FUNDAMENTAL:
}

The northeastern Pífano as an instrument of musical education in elementary school

El pífano del noreste como instrumento musical en la enseñanza primaria

Leonardo Araujo da Silva ${ }^{1}$

\section{Resumo:}

O trabalho proposto tem como objetivo relatar a experiência pedagógico-musical na oficina de pífano para crianças de 9 a 12 anos na disciplina do Projeto Práticas Musicais Comunitárias do SESC Casa Amarela em parceira com a Escola Municipal Severina Lira, onde foram realizadas atividades de apreciação, percepção musical e execução instrumental. A fundamentação teórica foi baseada na pedagogia musical (FONTERRADA, 2008; MATEIRO e ILARI, 2011), no pífano como instrumento musicalizador, performático (CUERVO, 2009) e no ensino coletivo de instrumentos (BARBOSA, 1997) e nas avaliações em sala (PERRENOUD, 1999).

Palavras-chave: Pífano; Ensino coletivo de instrumento; Práticas musicais comunitárias.

\begin{abstract}
:
This text aims to report the pedagogical musical experience in the pífano workshop for children from nine to twelve years. The pifano workshop was a discipline of the community musical practices project of SESC Casa Amarela in partnership with the Musical School Severina Lira. The theoretical foundation of this work is based on the musical pedagogy (FONTERRADA, 2008; MATEIRO; ILARI, 2011), on the pífano as an introductory instrument (CUERVO, 2009) and on the collective musical teaching (BARBOSA, 1997), and class evaluations (PERRENOUD, 1999).
\end{abstract}

Keywords: Pífano; Collective teaching of instruments; Comunity musical practices

\section{Resumen}

El trabajo propuesto tiene como objetivo relatar la experiencia pedagógica-musical, aplicada en la oficina de pífano en niños de 9 a 12 años., en la disciplina de Proyecto de Prácticas Musicales Comunitarias de SESC Casa Amarela en compañía de la Escuela Severina Lira. Dónde fueron realizadas actividades de apreciación, percepción musical y ejecución instrumental. La fundamentación teórica está basada en la pedagogía musical (FONTERRADA, 2008; MATEIRO e ILARI, 2011). El pífano como instrumento musicalizador, performático (CUERVO, 2009)., en la educación colectiva de instrumentos (BARBOSA, 1997).,y en las evaluaciones realizadas en el aula (PERRENOUD, 1999).

Palabras clave: Pífano; Enseñanza colectiva de instrumentos; Práctica musicales comunitárias.

${ }^{1}$ Universidade Federal do Rio Grande do Norte - UFRN 


\section{Introdução}

Este trabalho apresenta experiências e resultados das intervenções didático-pedagógicas musicais desenvolvidas através da inserção do pífano ${ }^{2}$ no ensino de música do Projeto Práticas Musicais Comunitárias do Sesc Casa Amarela. Essa experiência teve início em outubro de 2017 na Escola Municipal Severina Lira, que está localizada no bairro da Tamarineira em Recife-PE. A estrutura de funcionamento da escola atende alunos de 04 a 12 anos da Educação Infantil (Grupos IV e V), Ensino Fundamental ( $1^{\circ}$ ao $5^{\circ} \mathrm{Ano}$ ) e EJA - Educação de Jovens e Adultos (Módulos I, II, III) e oferece inclusão para crianças portadoras de necessidades educacionais especiais. Possui o quantitativo de $11 \%$ de alunos inclusos em turmas do ensino regular contando com acompanhamento pedagógico, social e salas com recursos multifuncionais.

A idealização do projeto Práticas Musicais Comunitárias surgiu com intuito de promover ascensão cultural nos bairros Nova Descoberta, Mangueira e Tamarineira, região metropolitana do Recife, situados na redondeza do Sesc Casa Amarela. A integração sociocultural faz parte da política desta instituição baseando-se no entendimento de que a cultura é uma ferramenta pertinente para transformação do indivíduo através da sociedade que incentiva a produção e difusão artística, atuando como elemento de articulação do desenvolvimento artístico-cultural por meios de cursos e oficinas em práticas musicais de canto coral, flauta doce, percussão, tecnologia musical e pífano, além dos concertos-didáticos ${ }^{3}$ ministrados pelos professores no caráter de aula expositiva, destacando aspectos da música, instrumentos musicais, repertório, compositores, gêneros e estilos musicais para o público das escolas inseridas na ação social do projeto.

Neste relato, é apresentada a prática realizada junto à turma da oficina de pífano na qual participaram 11 alunos com faixa etária de 9 a 12 anos destacando a acessibilidade de um dos alunos com deficiência portador da Síndrome de Down. Em seguida, será apresentada uma descrição da fundamentação teórica que embasou a prática pedagógico-musical, a abordagem metodológica desenvolvida durante as aulas e, por fim, serão apresentadas as considerações sobre a experiência docente.

\section{Metodologia}

Ao implementarmos a oficina de pífano na escola parceira Severina Lira em 2017, realizamos uma diagnose do ambiente escolar para reunir informações que nos subsidiassem no planejamento das atividades pedagógicas. Em sequência, demos início a primeira intervenção com os "Jogos Musicais" usando ludicidade com bolas e bingos sonoros, relacionado a criatividade, percepção melódica e rítmica para os alunos. Em nenhum momento foi utilizado termos técnicos e expressões musicais, o processo de aprendizagem naquele momento surgiu da curiosidade das crianças despertada, através do interesse de querer ouvir os sons dos jogos.

Na segunda intervenção foi realizados quatro concertos- didáticos, onde falamos brevemente sobre a história do instrumento, matéria-prima para fabricação, estilos musicais, bibliografias que falam a respeito do pífano e da biografia do pifeiro, flautista e compositor Egildo Vieira (1947-2015). Alagoano que contribuiu a partir dos anos 70 com suas composições para o enriquecimento da música pernambucana no Movimento Armorial de Ariano Suassuna.

\footnotetext{
${ }^{2} \mathrm{O}$ pífano tradicional é um instrumento cilíndrico com sete orifícios circulares, sendo um destinado ao sopro e os restantes aos dedos. Constituído por taboca, taquara, osso, caule de mamoeiro ou, ainda, como é mais explorado hoje em dia, com cano de PVC, uma alternativa para a escassez de matériaprima natural. É encontrado em três tamanhos: $65 \mathrm{~cm}$ a $70 \mathrm{~cm}$, chamado "régua-inteiro", $50 \mathrm{~cm}$, chamado "três-quartos", e $40 \mathrm{~cm}$, chamado "régua-pequena".

${ }^{3}$ Concerto-didatico sobre a biografia de Egildo Vieiria (1947-2015). Disponivel em: https://www.youtube.com/ watch=OAvh4TJoCsQ/ Acesso 12 set de 2020.
} 
A terceira intervenção durou 50 minutos, foi durante o turno vespertino no horário oficial da aula da oficina onde alunos interessados participaram de uma entrevista a fim de fornecer informações necessárias sobre seu interesse em participar das aulas de música. Mediante as entrevistas socioculturais, relataram suas disponibilidades e assiduidade nas aulas práticas e teóricas para seleção do grupo musical criado para escola. A priori foram entrevistados 25 alunos no qual selecionamos 11 e mais uma aluna portadora de síndrome de Dawn inserida nas aulas de música do projeto.

A oficina de pífano durou por dois trimestres sendo cada um com turmas diferentes. Primeira etapa iniciou no mês de outubro a novembro de 2017 e a segunda etapa iniciou no mês de março a junho de 2018. As atividades ocorreram uma vez por semana com duração de duas horas, as primeiras aulas foram dedicadas à apresentação do pífano e suas partes (orifícios, corpo) e à exploração dos sons que podem ser realizados pelo instrumento. Outros aspectos abordados foram: o aprendizado da postura corporal apropriada para a execução, o conhecimento dos pontos de apoio do instrumento - polegar direito, polegar esquerdo e boca -, e a articulação necessária para tocar o instrumento. Neste mesmo período foram introduzidas as primeiras notas musicais e suas respectivas digitações, partindo de atividades desenvolvidas com a percepção sonora através da imitação. Inicialmente foram adotados exercícios musicais tocados em intervalos de terças maiores e menores - primeira e segunda voz -, modelo da estética composicional das bandas de pífanos, explorando as articulações no instrumento.

Leituras rítmicas e solfejos foram atividades trabalhadas no desenvolvimento da prática instrumental, ambas auxiliadas por apostilhas com conteúdos elementares em música: clave, notação, pentagrama, compassos, escalas, além da apreciação musical dos estilos e gêneros através dos áudios e vídeos expositivos de bandas de pífanos e seus mestres em seus cotidianos. Através de pesquisas históricas sobre o instrumento, mostramos desde a confecção do instrumento, a composição e a execução musical como recurso pedagógico para aprendizagem. Para o aprendizado e a prática de novas notas musicais foi dado uma tabela com as posições corretas para emissão das notas, os pífanos utilizados nas aulas foram os afinados em Sol Maior ${ }^{4}$, o tipo mais usado no Agreste atualmente pelas nas bandas de pífanos que são conhecidos por "três quartos"”.

\section{Desenvolvimento}

Considerado um dos pilares da arte musical do Nordeste regional, o pífano historicamente é um instrumento ancestral.

\footnotetext{
O mais antigo registro de existência de um instrumento semelhante ao pífano no Brasil data de cerca de 2.000 anos atrás. Em 1983, estudos arqueólogos num sítio de pintura rupestre na Serra da Boa Vista município de Brejo da Madre de Deus, $195 \mathrm{~km}$ do Recife localizaram um cemitério indígena. Entre os 83 esqueletos resgatados, um deles possuía, entre os ossos de seus braços, uma flauta feita de uma tíbia humana, com um único furo adornado por um cinto de fibras vegetais (NETO, 2016, p. 24).
}

No Brasil, foi utilizado pelos indígenas em seus rituais de danças além da catequização e educação após a chegada dos jesuítas portugueses que o trouxeram nas caravelas no século XVI. O pífano é um dos instrumentos base da oralidade na cultura do campo constituída na esfera do mundo rural que detém uma relevância na cultura musical das regiões do Nordeste, Sertões e Agrestes, onde existe uma evidência cul-

\footnotetext{
${ }^{4}$ Padrão de afinação no qual pífano é confecccionado

${ }^{5}$ Pífano com 36 centímetros afinados em Sol maior comumente usados pelo pifeiros.
} 
tural e social constituída pelos pifeiros ${ }^{6}$, através das atuações das bandas de pífanos nos cortejos religiosos, festas cívicas, novenas e procissões.

Os números mais curiosos do seu vasto repertório são os duetos, música de caráter descritivo, destinadas a serem ouvidas e não dançadas é tradicional. A onça e o cachorro, de espirituosos efeitos instrumentais, mas os populares criam também peças músicas descrevendo histórias que inventam com personagens simbólicos, geralmente com o fito de satirizar ou fazer crítica social (GUERRA-PEIXE, 1958.p. 8).

São expressões culturais tradicionais que se apresentam para o mundo moderno na busca da preservação da cultura nacional através do conhecimento popular e da tradição passada de pai para filho desde o início do surgimento da banda de pífano no século XX. A cultura popular também esteve ligada ao processo de construção do nacionalismo musical ${ }^{7}$, construção de conhecimento na qual passou-se a ser elemento fundamental de identidade artística do Brasil. O pífano foi citado nos importantes movimentos musicais brasileiros do século XX que valorizaram a tradição oral encontrada na cultura popular. No Pós-Nacionalismo Musical pelo maestro Cesar Guerra-Peixe na Revista Brasileira de Folclore com o artigo Zabumba, orquestra nordestina ${ }^{8}$ e no Movimento Armorial pelo compositor Clóvis Pereira com o Terno de Pife $e^{9}$ composta em 1975, primeiro LP da Orquestra Armorial do Recife.

As primeiras produções fonográficas comercializadas surgiram no ano de 1970 pela Banda de Pífano de Caruaru que, após estes registros discográficos, tornou-se referência musical, grupos musicais seus contemporâneos dando continuidade aos estilos inserindo elementos eletrônicos ${ }^{10}$, instrumentos de cordas tangida ${ }^{11}$, friccionados ${ }^{12}$ e sopros ${ }^{13}$ de acordo com as composições na confecção de álbum: Quinteto Armorial $^{14}$; Orquestra Armorial ${ }^{15}$; Pife muderno ${ }^{16}$. Aqueles foram grupos instrumentais de referência nacional e internacional de música nordestina que durante suas pesquisas absorveram a linguagem musical dos gêneros característicos expressos na música da cultura do nordeste.

O nome "pife", que aqui se adota para designar o instrumento musical ocorrente no Nordeste brasileiro, consta como verbete de um único dicionário musical apenas, na "Enciclopédia da Música Brasileira: Erudita, Folclórica e Popular" (1998: 626). Nas duas versões do The New Grove Dictionary of Music (Mayer Brown, 1980: 112; Sadie, 1984) e na The Garland Encyclopedia of World Music (Crook, 1998: 210 e 325) constam os verbetes "pífano" (pijuano), "pífaro" (fife of Iberia) e, na última, "pífano" (na América Latina espanhola), "caboclo fifes" (pífanos) e "banda de pífanos" (band of fifes) (no Nordeste brasileiro). É dito na "Enci-

\footnotetext{
${ }^{6}$ Músico que confecciona seu próprio pífano e toca na banda de pífano.

${ }^{7}$ MARIZ, Vasco. História da música no Brasil. 2ª ed.:1983.

${ }^{8}$ Biografia de Cesar Guerra-Peixe. Disponível em: Acesso em 30/08/2017.

${ }^{9}$ Composição gravada no LP da Orquestra Armorial Disponível em: Acesso em 30/08/2017

${ }^{10}$ Sampler equipamento que armazena sons eletrônicos e loop station, pedal para controle de voz e efeitos.

${ }^{11}$ Violões, violas de 10 cordas

12 Violinos, violas, violoncelo, contrabaixo acústico.

${ }^{13}$ Flauta-transversal e clarineta.

${ }^{14}$ Quinteto Armorial formado em Recife pelo escritor Ariano Suassuna em 1970

${ }^{15}$ Orquestra Armorial grupo de música instrumental formado no Recife pelos músicos Jarbas Maciel e Cussy de Almeida em 1975.

${ }^{16}$ Pife Muderno é uma banda de música popular brasileira fundada em 1994 pelo músico Carlos Malta
} 


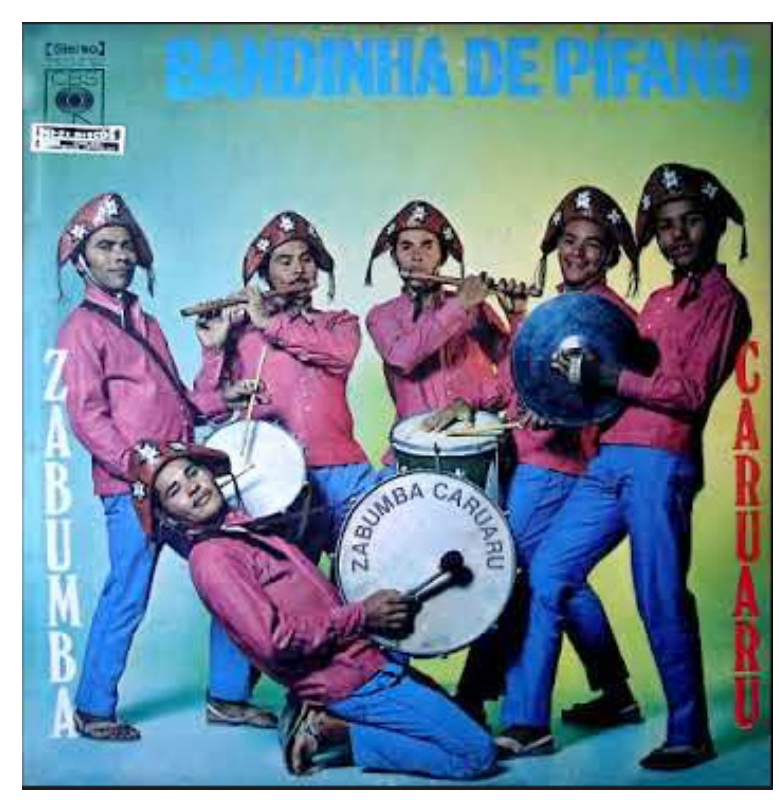

Figura 1 - Banda de pífano de Caruaru

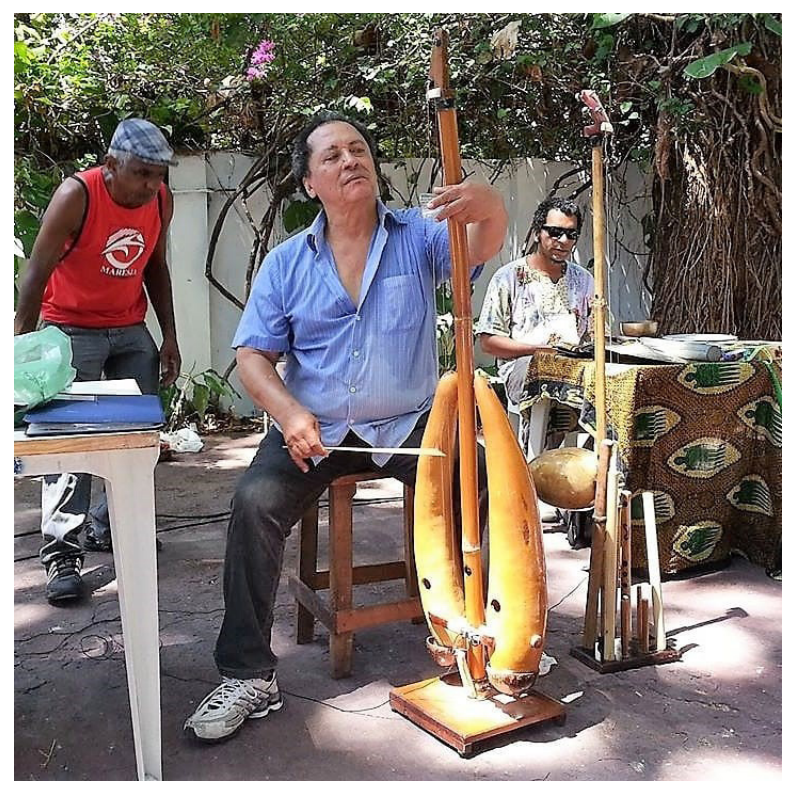

Figura 2 - Egildo Vieira do Nascimento (1947-2015)

clopédia da Música Brasileira”, em dicionários de língua portuguesa e na tese de mestrado de Marco Antônio Caneca, que o termo "pife" é uma corruptela de "pifre", este, por sua vez, seria a forma popular da pronúncia da palavra "pífaro". Caneca (1993: 66) ainda remete a raiz etimológica ao vocábulo "pfifer", médio-alto alemão e, citando Isaac Newton (que não é o ilustre físico inglês) 61, refere-se a possível derivação do termo "pífano" a alguma associação feita ao nome de um certo Coronel Pfeifer, oficial germânico que primeiramente utilizou um instrumento de sopro, sem chaves e agudo, em um regimento militar.

Em virtude da grande profusão de nomes e "confusão" das características na classificação do instrumento, optou-se pelo termo "pife" por ser esta a forma de uso corrente usada pelos dois pifeiros contactados da região agrestina do estado de Pernambuco no Nordeste brasileiro 62. Além disso, o termo é útil para evitar as confusões entre a referência ao instrumento nordestino e aos seus assemelhados em contex-

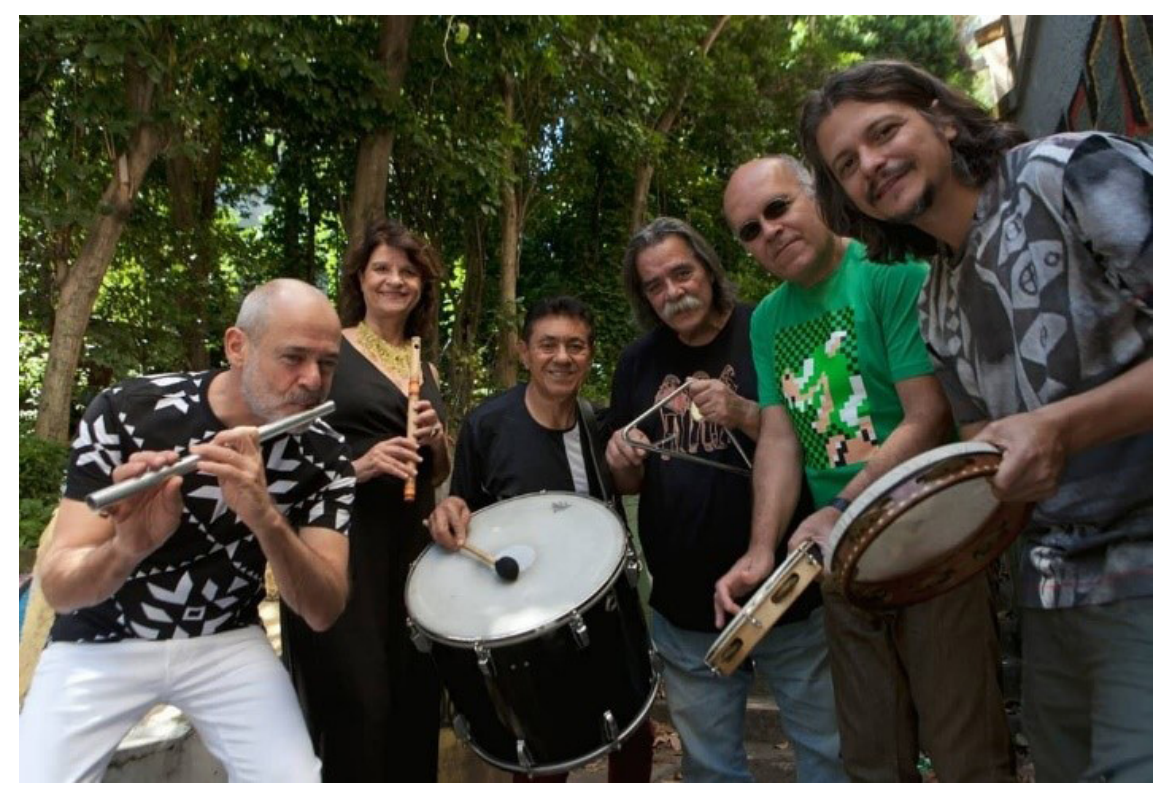

Figura 3 - Pife Muderno 
tos outros como no uso do pífano em Portugal ou em países da América Latina, onde lá, o termo "pífano" pode vir a caracterizar uma flauta longitudinal (PIRES, 2005).

A matéria prima usada comumente para fabricação dos pífanos é a madeira conhecida por taquara e taboca, gramíneas de espécies parecidas com o bambu. Por causa do desaparecimento da madeira na região, alguns pifeiros optaram por utilizar o pvc e o metal como matéria prima para fabricação de novos pífanos. A formação do pífano é em "régua inteira", "três-quartos de régua" e "meia régua", podem ser confeccionados em cada material (em espécies de taquara ou taboca, pvc e metal).

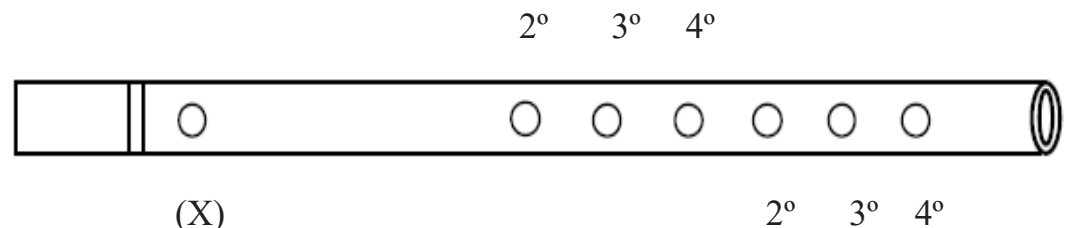

$\mathbf{X}$ : embocadura

ME: $2^{\circ}, 3^{\circ}$ e $4^{\circ}$ dedo

MD: $2^{\circ}, 3^{\circ}$ e $4^{\circ}$ dedo

Figura 4 - Pífano

Os tipos de afinações: três-quartos de régua, "A 3"17 (lá maior); meia régua, "C 3" (dó maior); régua inteira, "G 3" (sol maior). Portanto, constatamos que a afinação por quintas ascendentes não ocorre no pife e a construção de tipos visando a uma funcionalidade específica.

O processo de fabricação é manual, vem do manuseio de ferro e fogo com medidas, através da palma da mão usando o polegar e o dedo mínimo, o pifeiro vai furando a madeira com um vergalhão incandescente produzindo os setes orifícios à posição do tubo no ato da furação do pífano.

Os gêneros musicais comumente tocados por esses conjuntos são ritmos como dobrados, marchas, valsas, choros e forrós. Suas melodias geralmente vêm da observação e da interação que esses homens têm com o meio ambiente, ou seja, com as "paisagens sonoras” 24 onde estão inseridos, em geral, ambientes rurais. (SILVA, 2013.p. 30)

João Alfredo dos Santos, popularmente conhecido como Mestre João do Pife, nasceu no Sítio Xambá, município de Riacho das Almas, Pernambuco. Aprendeu a arte de tocar e confeccionar pífanos através do seu pai. Viajou em turnê pela Europa realizando apresentações artísticas culturais, gravou seu primeiro disco em 2005 e realiza diversas participações em gravações de discos de artistas nacionais e internacionais.

[...] A banda de pífanos foi criada para tocar novena quando eu sai de casa e vim para Caruaru eu fui percebendo na feira que tinha que criar coisas mais animadas, porque aqui não era lugar de novena. Você chegava na feira tinha o cordel, via um trio de forro, um violeiro um cantador isso aí eu fui me espelhando e vi que tinha que aumentar a bagagem de tamanho, porque a novena a gente já tinha, vamos se dedicar a outros estilos. Eu não estudei, trabalhei na roça com meu pai, mas através do pife conheci vários países. Eu nasci naquela casinha simples no pé da serra mais o meu pai e fui me dedicando a

\footnotetext{
${ }^{17}$ Nota musical que padronizando a extensão e a afinação do instrumento na escala geral
} 


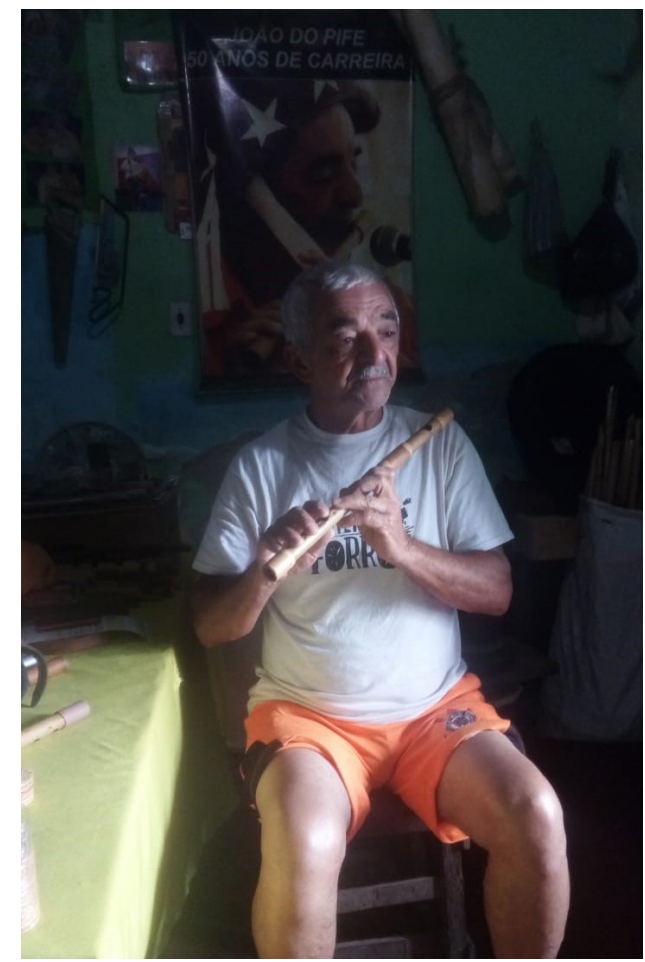

Figura 5 - João do pife toca pife e foi uma dedicação boa. Hoje o pife faz parte da minha vida, o pife me deu casa para morar em Caruaru criei essa família toda hoje estou com 76 anos vivo do pife. O pife me representa tudo na vida, é uma coisa que corre nas veias eu não estudei, mas através do pife eu fiz muitas amizades boas e cada vez eu aumento essas amizades. Eu andei de avião, o que que iria fazer lá fora se não fosse o pife, eu não estudei e vim da roça ninguém vai levar um agriculto para fora. Meu pai era o mestre era tudo favorável a gente de dia a noite, ali foi a hora da gente se dedicar. Quando é como um professor, você tem os dias marcado para você está na aula e na nossa casa o mestre foi nosso pai, então de dia noite a gente tocava pífano naquela casa eu e meu irmão levávamos aquilo numa brincadeira, porque aquilo corria nas nossas veias, uma coisa passada de pai para filho. O mestre da gente foi pai naquele estilo de novena, nós não tínhamos um professor para tocar outras coisas. O estilo de pai era novena, quando eu cheguei em Caruaru eu fui percebendo que tinha que mudar par enfrentar a cidade, fui me espelhando e mudando o repertorio para tocar outras coisas, tem que ter um repertorio de novena bom e grande para não "ta” repetindo música. (SANTOS, 2019)

A valorização da cultura nordestina, sobretudo pernambucana, está explicita nos interesses da proposta pedagógica da oficina, principalmente na conservação da tradição musical do pífano, vista na região do Agreste, sobretudo na cidade de Caruaru, onde se concentra treze bandas de pífanos formadas no campo por homens, mulheres e crianças, é o maior número de bandas atuantes numa única cidade. Os objetivos de ensino aprendizagem surgem através duma articulação entre a teoria e a prática contextualizada a respeito da história do instrumento, do cotidiano social dos pifeiros e da performance, que são habilidades necessárias para o aprendizado, didática que estimula a prática instrumental dos alunos com o pífano em busca da conservação dos estilos musicais genuinamente autêntico no que afirma autora Cristina Eira na sua dissertação:

O fato de ter percorrido uma trajetória do campo para cidade permite estudar transformações e permanências dos significados sociais que apresenta a relação com a tradição e a identidade cultural e as duas dimensões presentes na cultura oral do Brasil: de um lado, o seu modo de pensar nativo ligado à cultura de origem, intrínseco ao seu modo de fazer de conhecer, conceber a música. De outro, o processo de assimilação e transformação da cultura local no contexto urbano e moderno das cidades, as permanências e reafirmações dos elementos culturais tradicionais na sociedade urbana (VELHA, 2008, p. 22).

Dessa forma as aulas aconteceram de maneira coletiva nas quais os alunos poderiam diagnosticar suas evoluções diante das observações feitas nas aulas expositivas, bem como durante a prática instrumental coletiva, atentar-se para os conceitos técnicos, teóricos, científicos, históricos, artísticos e filosóficos, possibilitando os diálogos que são fundamentais para o aprendizado dos conteúdos de cada etapa. Entendendo que:

A interação permite ao grupo realizar trocas entre práticas e saberes afetivos e cognitivos entre os próprios sujeitos com a música e entre eles e os professores. Participando ativamente do processo de aprendizagem coletivo e individual, os sujeitos fortalecem sua autonomia de pensamento, autoestima, criatividade na resolução de problemas entre outros aspectos do desenvolvimento musical (CUERVO, 2009, p. 64). 
Através das atividades lúdicas e aprendizagem dos conceitos básicos revelados com a prática da experimentação e imitação, o público infantil compreende de forma mais prática e espontânea a música, desenvolvendo a percepção musical, cognição além da motricidade e a capacidade de interação com o meio e com os instrumentos musicais. Dentre estas práticas, damos destaque nesta comunicação à metodologia da oficina de ensino do pífano, com base na Lei $13.278^{18}$ do ensino de música nas escolas e das pedagogias dos métodos ativos idealizados pelos pedagogos musicais da primeira geração do século $\mathrm{XX}^{19}$ de introdução no Brasil: Émile-Jaques Dalcroze, Edgar Willems, Zoltán Kodály, Carl Orff e Shinichi Suzuki.

O que Dalcroze entende por educação musical ultrapassa o conceito comumente atribuído a essa expressão, de ensino de música para crianças. Para ele, toda ação artística é um ato educativo e o sujeito a que se destina essa educação é o cidadão, seja ele criança, jovem ou adulto (FONTERRADA, 2008, p. 128).

Foram estes métodos propostos nas atividades da oficina no caráter de explorar conceitos básicos da música: ritmo, melodia, harmonia, timbre, propriedades do som, alturas, intensidades, improvisação, imitação associados ao movimento, percepção, além da prática instrumental coletiva baseadas nos conceitos de ensino de instrumento do prof. Egíldo Vieira (1947- 2015) ${ }^{20}$ e do método de ensino coletivo de instrumentos de bandas, o "Da Capo", de Joel Barbosa (1997). Os Jogos Musicais foram realizados como parte de um processo da prática docente propondo o uso de outra maneira de atender a demanda da educação musical no âmbito da Educação Básica conforme orienta a lei 13.278 proporcionando aos estudantes do $4^{\circ}$ ano do fundamental I uma interação e a introdução da Educação Musical, vivências estas que nos ajudaram a diagnosticar o conhecimento prévio musical de cada estudante, seus "potenciais" e "limitações" que garantirão conceitos elementares da música.

Entre outros ganhos, percebe-se que o contato preliminar com o ambiente escolar foi fundamental para criação de um grupo musical, a "Bandinha de Pífano", que se encontra em curso através do respectivo projeto para o desenvolvimento dessas ações. Nos apropriamos dos "métodos ativos" abordados nos livros "De Tramas e Fios" (FONTERRADA, 2008) e "Pedagogias em Educação Musical” (MATEIRO; ILARI, 2011).

\section{Resultados}

A cada aula um novo estágio era proposto. As etapas de aprendizagem da prática no pífano eram de acordo com o desempenho de cada aluno, por etapas concluídas era acrescentada uma nova lição, era introduzida uma nova atividade técnica no instrumento. Conceitos sobre os aspectos técnicos da respiração, postura corporal e leitura musical discutidos nas aulas anteriores eram revisados nas aulas seguintes. Havia comumente uma rediscussão sobre os conteúdos programáticos buscando sempre o nivelamento da turma. Assim era o processo de avaliação, através da organização didática dávamos seguimento à aprendizagem de novas tarefas, priorizando a percepção musical por meio do "tocar de ouvido"21, pois era cobrada todo início de aula o fazer musical.

\footnotetext{
${ }^{18}$ BRASIL. Lei 13.278, de 2 de maio de 2016. Altera o § 6 o do art. 26 da Lei no 9.394, de 20 de dezembro de 1996, que fixa as diretrizes e bases da educação nacional, referente ao ensino da arte. Disponível em: . Acessado em: 5 dez., de 2018

${ }^{19}$ Cabe destacar que os "métodos ativos" chegaram ao Brasil a partir da década de 1950 e foram gradualmente sendo aplicados em contextos restritos, especialmente aqueles relacionados ao ensino particulardemúsica(FIGUEIREDO,2013,p.1).Disponívelemhttp://www.amusicanaescola.com.br/pdf/Sergio_Luiz_Figueiredo.pdf.

${ }^{20}$ Alagoano nascido na cidade de Piranhas -AL foi pifeiro, flautista e compositor do Movimento Armorial

${ }^{21}$ Definição que se dar na tradição oral para aquele que não depende da partitura como recurso de reprodução.
} 


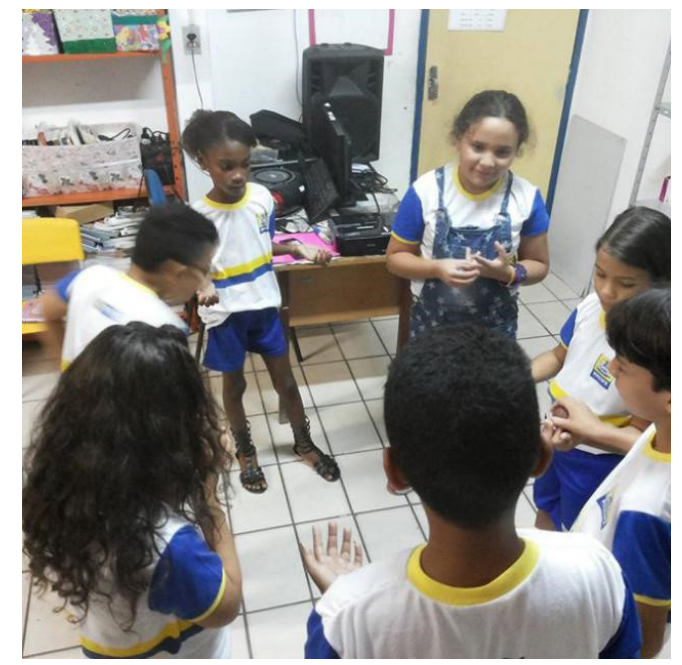

Figura 6 - Atividade jogos musicais

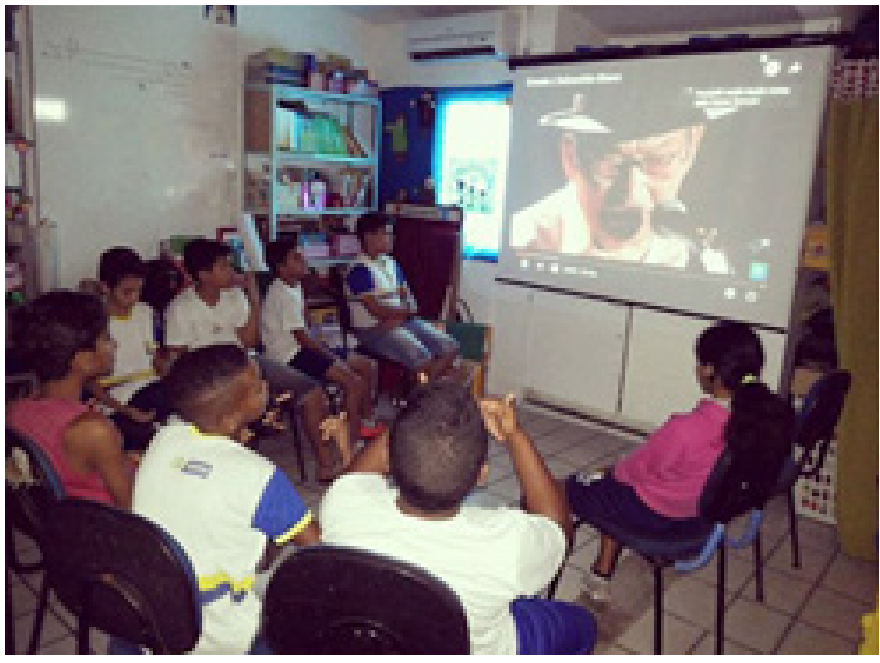

Figura 7 - Aula expositiva documentário sobre Sebastião Biano

A avaliação formativa assume todo seu sentido no âmbito de uma estratégia pedagógica de luta contra o fracasso e as desigualdades, que está longe de ser sempre executada com coerência e continuidade. (PERRENOUD, 1999. p. 9)

Apesar de terem apresentado interesse e rendimento nas atividades, foi observada uma desmotivação dos alunos no período de adaptação, pois tivemos que conciliar a oficina durante o turno escolar, essa questão refletiu na assiduidade do grupo e na prática diária do instrumento

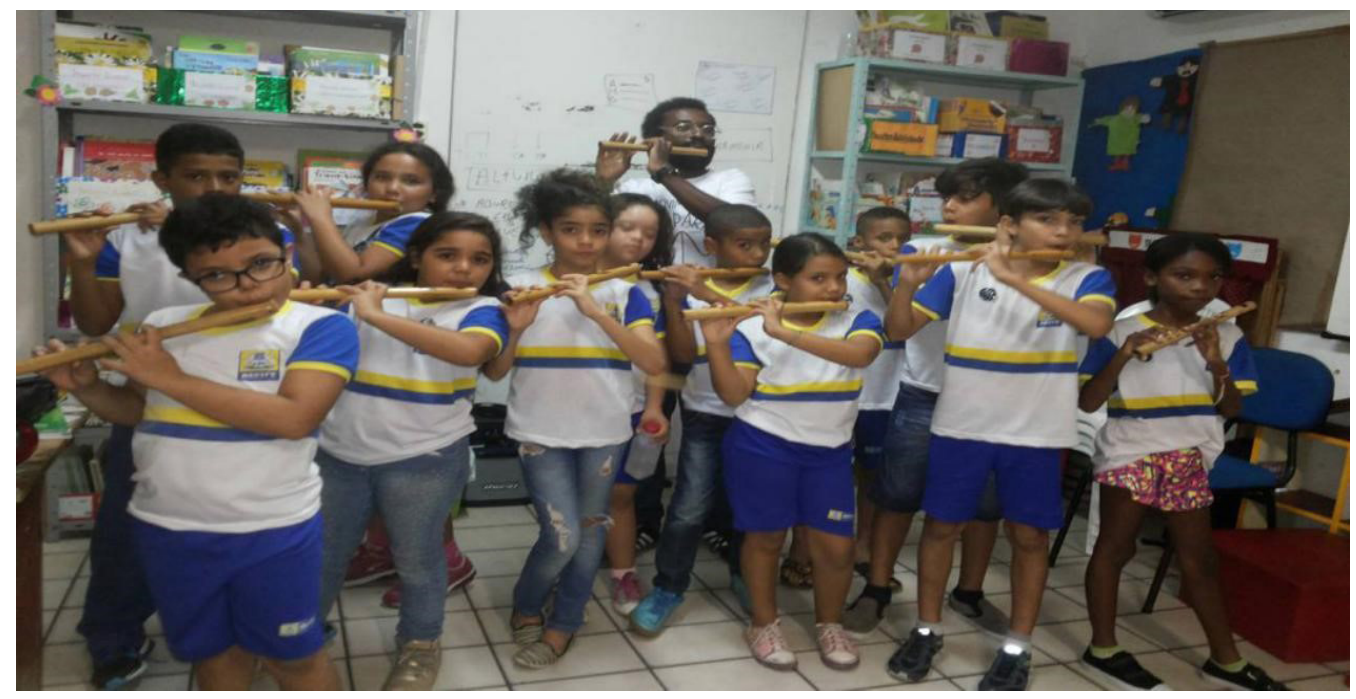

Figura 8 - Bandinha Severina Lira

\section{Resultados}

A interação dos alunos nas atividades da "bandinha de pífano" foi satisfatória. Percebeu-se, ao longo e após a realização das atividades, facilidades e dificuldades dos participantes na execução das tarefas. Notávamos o interesse da maior parte dos alunos no conteúdo apresentado enquanto outros não se interessaram por essas ações. Contudo, os trabalhos foram realizados com êxito, o que contribui, de certa maneira, com a inserção da oficina de pífano no respectivo ambiente escolar. 
Por consequente, ressaltamos que as práticas musicais comunitárias é uma ação importantíssima para os bairros Tamarineira, Nova descoberta, Mangabeira, adjacentes do Sesc Casa Amarela, bem como para a área da Educação musical, por facilitar o trânsito e o diálogo entre a instituição Sesc Pernambuco e as escolas de educação básica e por proporcionar experiências docente e formativa aos oficineiros, além de fortificar a vivência da música como parte da formação humana no respectivo ambiente escolar.

\begin{tabular}{|lcll|}
\hline \multicolumn{3}{|l}{ Turma 2017} & \multicolumn{2}{l|}{ Turma 2018 } \\
Aulas de setembro a novembro & Aulas de abril a junho \\
Alunos entrevistados & 25 & Alunos entrevistados & 25 \\
Selecionados & 10 & Selecionados & 12 \\
Desistentes & 3 & Desistentes & 1 \\
Número de aulas & 14 & Número de aulas & 13 \\
Assiduidade & $75 \%$ & Assiduidade & $85 \%$ \\
Avaliações & 3 & Avaliações & 3 \\
\multicolumn{2}{|c}{ Resultado da oficina } & Resultado da oficina \\
Sem participantes para formação banda & Dez participantes para formação banda de \\
\multicolumn{2}{r}{ de pífanos. } & \multicolumn{2}{c}{ pífanos. } \\
\hline
\end{tabular}

Tabela 1 - o panorama das aulas de acordo com o semestre letivo e os respectivos resultados das atividades das oficinas

\section{Referências}

BARBOSA, Joel. Produção científica em ensino coletivo de instrumentos de banda e o terceiro setor: avaliação e perspectivas. In: Anais do XIV Encontro Anual da ANPPOM. Porto Alegre: 2003, v.1, p. 1-5.

CUERVO, Luciane. Concepções de musicalidade entre estudantes de licenciatura de música: um estudo nas modalidades de ensino presencial e à distância. In: Anais do XIII Encontro Regional da ABEM. Porto Alegre: IPA Metodista, 2010.

FONTERRADA, Marisa Trench de Oliveira. De tramas e fios: um ensaio música e educação. 2. Ed. São Paulo: Editora UNESP; Rio de Janeiro: Funarte, 2008.

GUERRA-PEIXE, Cesar. Zabumba, orquestra nordestina. In: Revista Brasileira de Folclore. Rio de Janeiro, 10(26), jan/abr., 1970, pp.15-38.

Lei 13.278. Disponível em: http://www.planalto.gov.br/ccivil_03/_Ato2015-2018/2016/Lei/L13278.htm Consultado em: 21 mai. de 2019.

MARIZ, Vasco. História da música no Brasil. 2a edição. - Rio de Janeiro: Civilização Brasileira, 1983.

MATEIRO, T.; ILARI, B. (Org.). Pedagogias em educação musical. $1^{\text {a }}$ edição -Curitiba: Ibpex, 2011. 
NETO, Eduardo Monteiro de Lima et al. Pífanos do Sertão. 1ª edição - Recife: FacForm, 2016.

PERRENOUD, Philippe. Avaliação: da excelência à regulação das aprendizagens - entre duas lógicas. $1^{\mathrm{a}}$ edição - Porto Alegre: Artes Mádicas Sul, 1999.

PIRES, Hugo Pordeus Dutra. A malícia do pife - Caracterização Acústica e Etnomusicológica do Pife Nordestino. Dissertação (Mestrado em Música - Musicologia). Rio de Janeiro: Escola de Música da Universidade Federal do Rio de Janeiro, 2005.

SANTOS, João Alfredo. Entrevista de Leonardo Araujo da Silva em 20 de junho de 2019. Caruaru. Áudio SILVA, Daniel Rodrigo Félix. A confecção artesanal do pífano no Nordeste brasileiro. Monografia (Licenciatura em Plena Música). Ceará: Centro de Humanidades da Universidade Estadual, 2013.

VELHA, Cristina Eira. Significações sociais e simbólicas na trajetória da banda de pífano de Caruaru e a problemática história do estudo da cultura de tradição oral no Brasil (1924-2006). Dissertação (Mestrado em Música - Etnomusicologia). São Paulo: Universidade Federal de São Paulo, faculdade de Filosofia, Letras e Ciências humanas, 2008.

Recebido em 31/10/2020

Aceito em 23/11/2020 
